\title{
Yara pipeline transportation of thickened tailings
}

\author{
E Vlot Weir Minerals Netherlands B.V., The Netherlands \\ M Riihimäki Weir Minerals Netherlands B.V., Finland
}

\begin{abstract}
Yara has operated the Siilinjärvi mine in Finland since 1979. Each year, the mine produces around $1 \mathrm{M} t$ of apatite concentrate from $11 \mathrm{M}$ t ore, and it is Western Europe's only phosphate mine. The concentrate is processed into phosphoric acid in Siilinjärvi and then further into fertilisers and feed phosphates in Yara's plants in Finland and Norway. The tailings have to be deposited at the Siilinjärvi plant, and the existing tailings storage facility (TSF) was reaching full capacity. Yara did an extensive study for future storage of tailings and decided to adopt a thickened tailings solution. The tailings would be thickened to $68-72 \%$ by weight in order to build $a+2^{\circ}$ sloped deposit, thereby sufficiently increasing the storage capacity.

Weir Minerals supported Yara from the pilot plant operation, continuing in the sizing of the full plant pumping system until execution and commissioning of the paste pumping plant. After evaluation of the pilot plant results, it was concluded that additional loop testing was required in order to determine the pressure gradients for the full plant pumping system. During project execution, Weir Minerals supplied a complete pumping solution to Yara, comprising of three GEHO ${ }^{\circledR}$ TZPM 2000 pumps and Warman ${ }^{\circledR} A H^{\circledR}$ 10/8F centrifugal pumps. In addition, Weir Minerals supplied the required Isogate ${ }^{\circledR}$ hydraulic-actuated slurry valves, suction strainers, slurry instrumentation and developed the functional description for Yara's distributed control system (DCS). The system is operated remotely from the plant DCS without any programmable local control (PLC) devices to enable future unmanned, automated operation of the complete pump station. Local control can be established through tablets which are connected to the DCS, providing diagnostic performance reviews of the pump and plant operation. The system was successfully commissioned in February 2017, with slurry solids concentrations reaching planned targets, resulting in a slope at the TSF of approximately $3^{\circ}$. This paper describes the development of the project from the feasibility to the commissioning stage, highlights the main challenges and reflects Yara's future expectations for plant development and operations at the Siilinjärvi mine.
\end{abstract}

Keywords: thickened tailings disposal, piston diaphragm pumps

\section{Introduction}

Yara has operated the Siilinjärvi mine in Finland, Western Europe's only phosphate mine, since 1979. The mine produces around $1 \mathrm{Mt}$ of apatite concentrate from $11 \mathrm{M} \mathrm{t}$ ore annually. The concentrate is processed into phosphoric acid in Siilinjärvi. It is then further processed into fertilisers and feed phosphates in Yara's plants in Finland and Norway. The tailings have to be deposited at the Siilinjärvi plant, and the existing tailings storage facility (TSF) was reaching full capacity. Yara did an extensive study for future storage of tailings and started with a pilot project.

\section{Pilot plant}

In 2012, Yara started with the operation of a pilot thickener to investigate the possibility of applying a thickened tailings disposal (TTD) concept for their tailings storage. The goal of the pilot project was to prove:

- The thickening concept.

- The pumpability of the slurry.

- The disposal concept. 
This paper focuses predominantly on the pumpability of the slurry.

The pilot thickener was able to process 100 tph of dry tailings. For transportation of the slurry, a Warman ${ }^{\circledR}$ AHF3 centrifugal pump was used.

The pilot pump duties were $130 \mathrm{~m}^{3} / \mathrm{hr}$ against $400 \mathrm{kPa}$. The pump had to pump the slurry through a $500 \mathrm{~m}$ long, $100 \mathrm{~mm}$ ID diameter high-density polyethylene (HDPE) pipeline. During the trial period, it became clear that the suction conditions of the centrifugal pump were not favourable, as the slurry feed from the thickener was frequently stalling. After changing the cone angle of the thickener, suction conditions improved and the test could continue at higher concentrations. While reaching target concentrations between 65 and $68 \%$ by weight, the available discharge head of the centrifugal pump proved to be insufficient even after increasing the pump speed and changing the electric motor.

In order to allow for a continuation of the test, Yara rented a $\mathrm{GEHO}^{\circledR}$ crankshaft driven piston diaphragm pump, model TZPM 180. This pump was able to generate a flow of $100 \mathrm{~m}^{3} / \mathrm{hr}$ against a discharge pressure of 4,000 $\mathrm{kPa}$. A typical cross-section of this pump type can be found in Figure 1. In a piston diaphragm pump, a diaphragm separates the moving pump parts from the abrasive slurry and the only wear parts are the pump non-return valves. In addition, it provides for high efficiency in the order of $90 \%$ (including motor and variable frequency drive). For the feed pump, a constant speed drive was used, providing flow and pressure as required by the positive displacement (PD) pump.

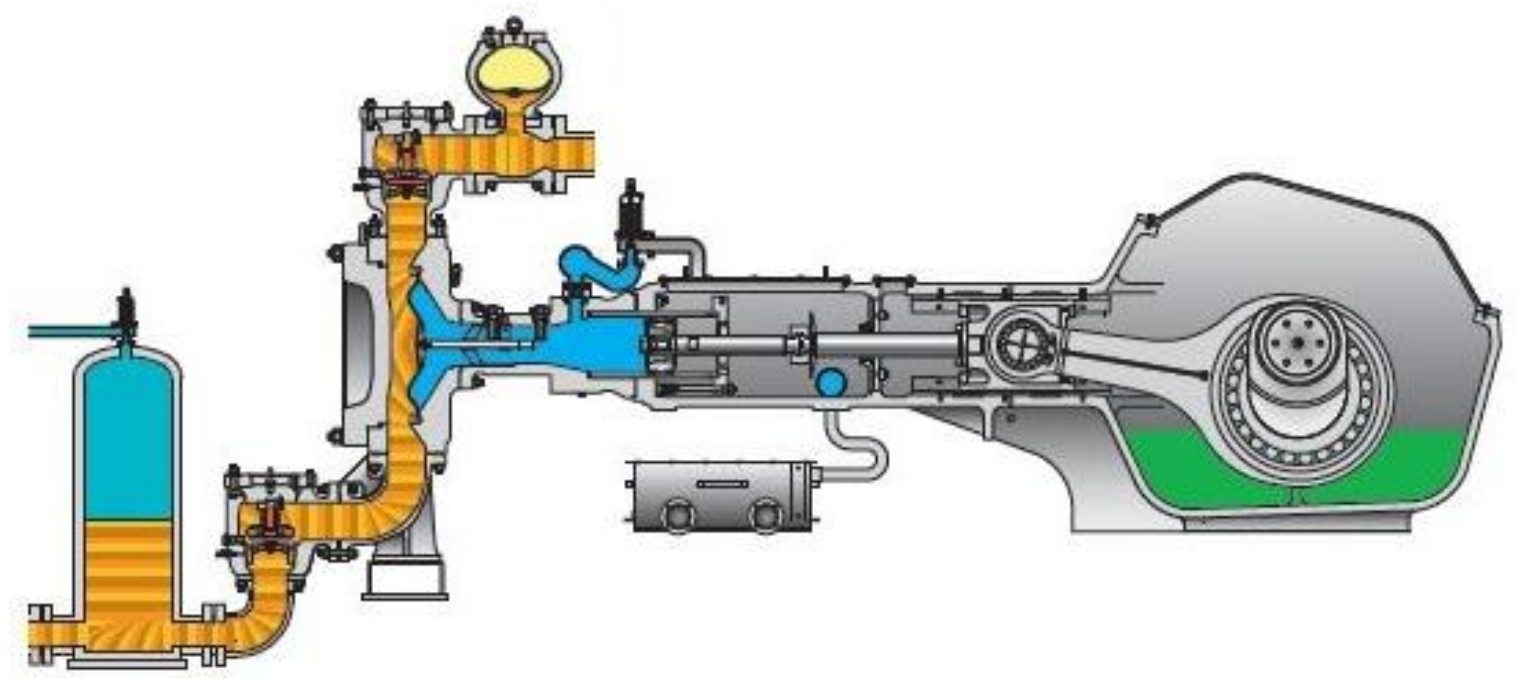

Figure 1 Cross-section of triplex piston diaphragm pump

After installing the PD pump, the pilot plant was able to run without any problems and the thickening and pumping concept, as well as tailings angle of repose at the TSF, could be proven. It was, however, observed that there were large changes in operating conditions (densities and pressures) depending on the type of ore that was handled by the crushing plant. A small increase in density sometimes resulted in a substantial change in pumping behaviour. The general pilot plant operating conditions are presented in Table 1.

Table 1 Operational PD pump data of pilot plant

\begin{tabular}{lllll}
\hline $\begin{array}{l}\text { Solids } \\
\text { concentration (\%) }\end{array}$ & $\begin{array}{l}\text { Density } \\
\left(\mathbf{k g} / \mathbf{m}^{3}\right)\end{array}$ & $\begin{array}{l}\text { Flow } \\
\left(\mathbf{m}^{3} / \mathbf{h r}\right)\end{array}$ & $\begin{array}{l}\text { Suction } \\
\text { pressure }(\mathbf{k P a})\end{array}$ & $\begin{array}{l}\text { Discharge } \\
\text { pressure }(\mathrm{kPa})\end{array}$ \\
\hline $64-66$ & $1,721-1,750$ & $23-126$ & $130-410$ & $150-330$ \\
$67-69$ & $1,771-1,811$ & $8-113$ & $150-660$ & $150-450$ \\
$70-72$ & $1,833-1,877$ & $12-108$ & $80-510$ & $180-900$ \\
\hline
\end{tabular}




\section{$3 \quad$ Slurry testing and pump sizing}

After the trial period, the test results were reviewed and used to size the equipment for a possible full-scale project. Based on the slurry characteristics, it was concluded that the best option for slurry transportation would be a PD pump, and more specifically a crankshaft-driven piston diaphragm pump.

Based on the required plant throughput (tph), the required pump flow was finalised. In order to determine the PD pump pressure requirement, the data generated during pilot plant operation was reviewed. It was noted that although there was a substantial amount of data available, the data were not conclusive and could not provide sufficient base for size of the full-sized system.

At numerous data points, it could be concluded that the PD pump flow was higher than the design flow. This implied that the booster pump was pumping straight through the PD pump, pushing the non-return valves in their open position. So despite the vast amount of data, the results were not all usable for determining the pump pressure requirements. The pilot plant was built to prove the general concept, rather than being a test loop in which the relationship between flow rate and pressure gradients are measured in a controlled manner. It was decided that additional loop testing had to be done in order to determine pipeline pressure gradients. Before loop testing started, the general properties of the tailings were determined through bench top testing. The results are presented in Table 2.

Table 2 Extract of bench top study results

\begin{tabular}{ll}
\hline Property & Value \\
\hline Solids density & $2,878 \mathrm{~kg} / \mathrm{m}^{3}$ \\
$\mathrm{~d}_{90}$ & $600 \mu \mathrm{m}$ \\
$\mathrm{d}_{50}$ & $200 \mu \mathrm{m}$ \\
$\mathrm{d}_{25}$ & $70 \mu \mathrm{m}$ \\
$\mathrm{pH}$ & 9.8 \\
Freely settled bed full fraction & $38.6 \% \mathrm{v}$ or $64.4 \% \mathrm{~m}$ \\
Maximum settled bed full fraction & $41.8 \% \mathrm{v}$ or $67.4 \% \mathrm{~m}$ \\
\hline
\end{tabular}

Pressure gradient tests were conducted for two different pipeline diameters. At mixture velocities lower than the deposition velocities, the pipe loop operated with a stationary bed. The slurry behaved as fast-settling heterogeneous slurry. In order to translate the results of the loop gradient tests into a model, the concept of two-layer flow according to the Saskatchewan Research Council two-layer model was used (Shook \& Rocco 1991).

Referring to Figure 2, the model is considered to be generally following the trends in the data, in terms of velocity and slurry concentration. In contrast to the pipe loop scenario where the in situ solids concentration is constant, in a continuous operating pipeline the transported concentration is constant. The pressure gradient increases through the area reduction as a result of the settled bed (either stationary or sliding). Figure 3 shows the friction pressure gradient trend as determined by the model for a continuous operating pipeline system with a fixed transported concentration with pipe diameter and slurry concentration range identical to those in the pipe loop tests. 


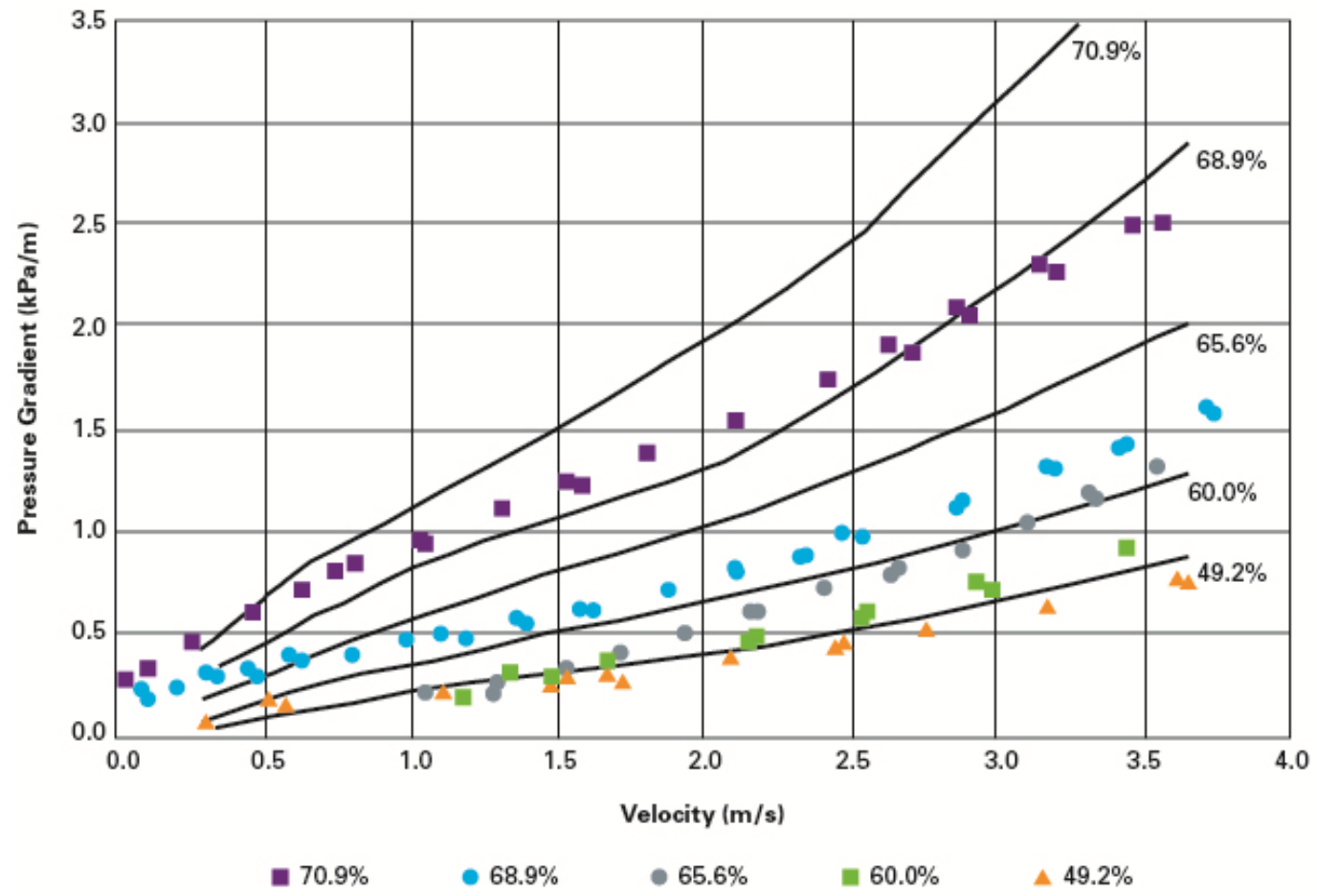

Figure 2 Pipe loop test data and two-layer model (150 NB)

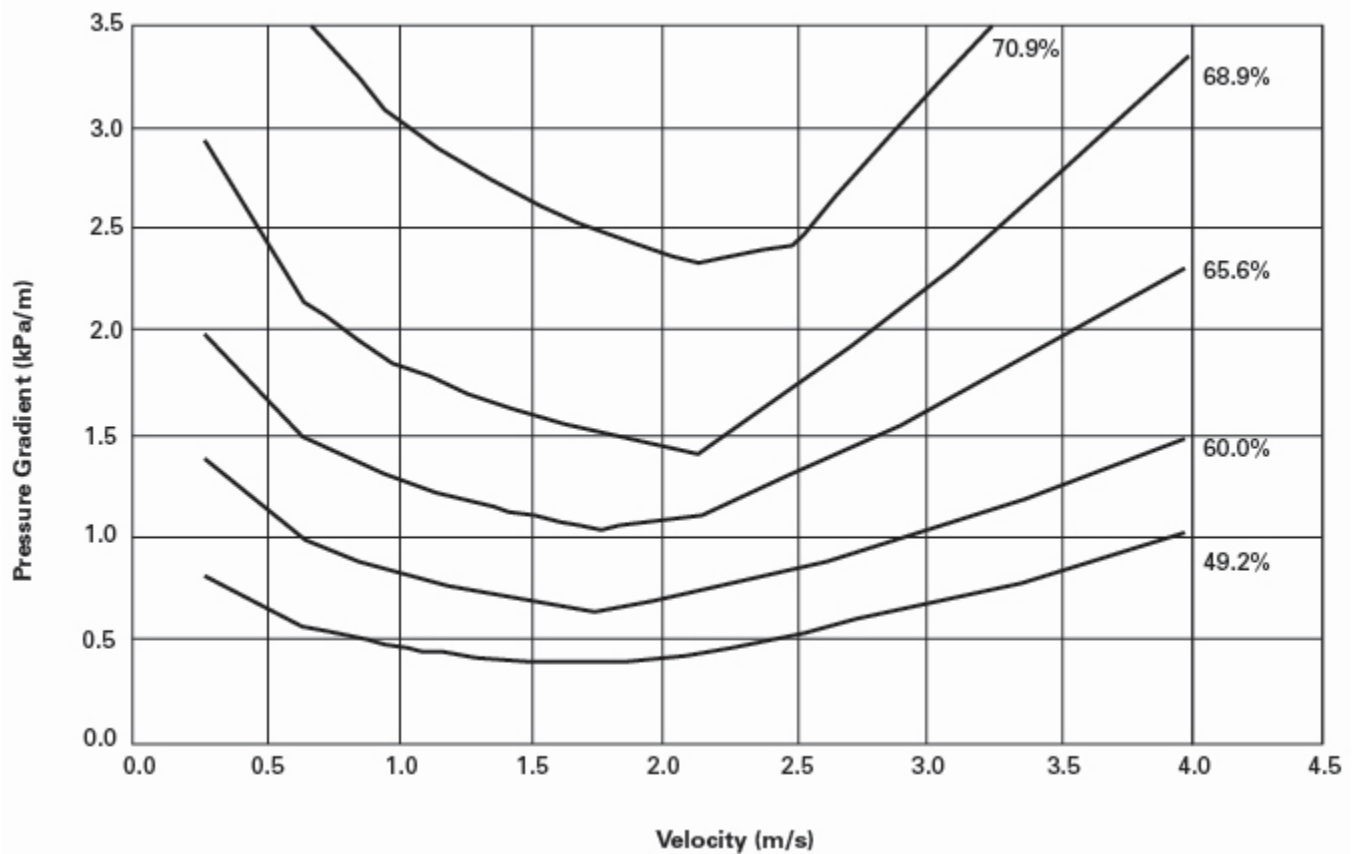

Figure 3 Two-layer model for continuous operating pipeline (150 NB)

Comparison of the pilot plant site test data and the two-layer model pressure gradient prediction for the continuous operating pipeline are considered to be in agreement with the mean and trend values, although there is scatter in the site data. Figure 4 shows the relationship between slurry flow rate, solids throughput and slurry concentration. 


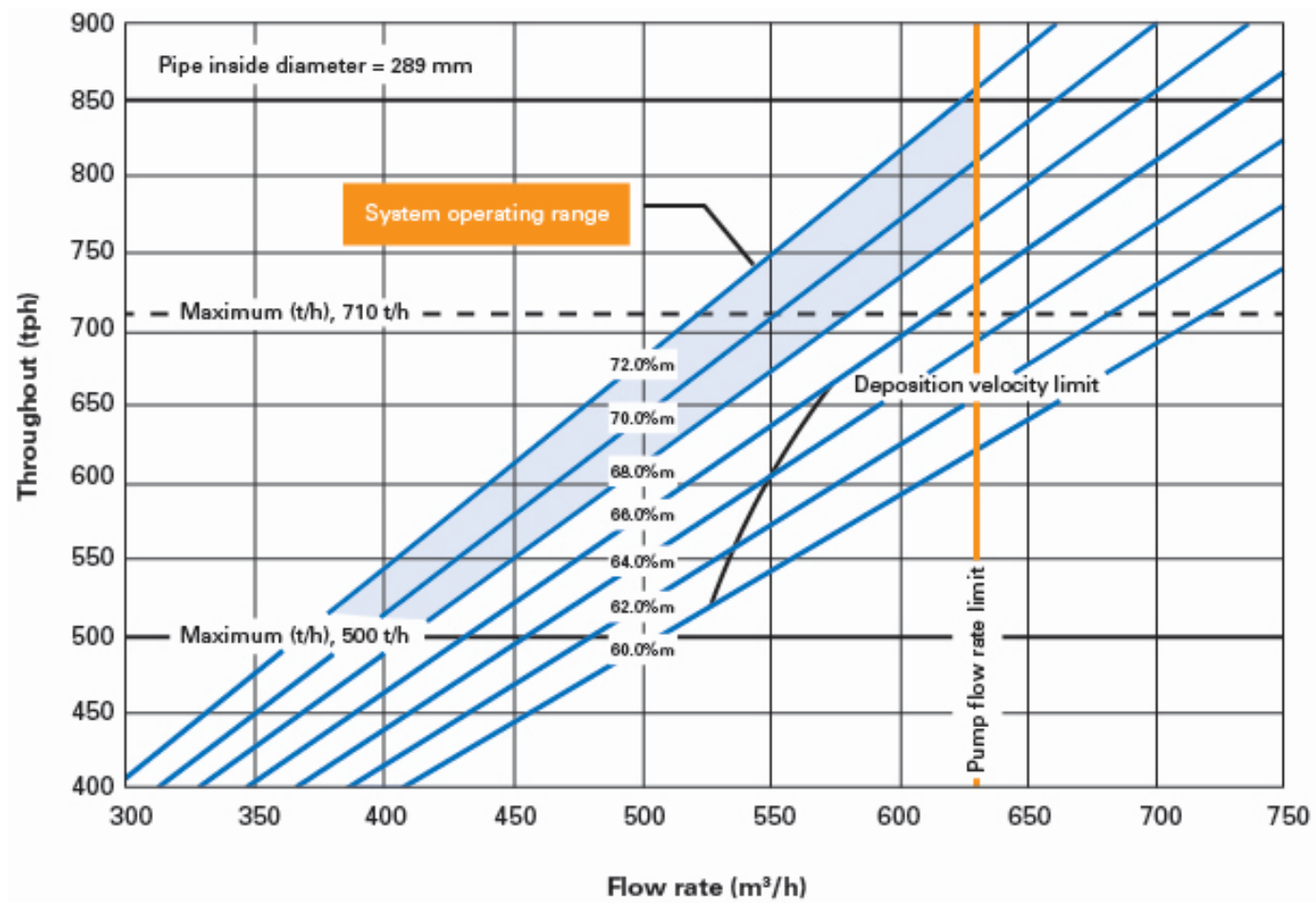

Figure 4 Operating range chart

The test work has indicated that at concentrations greater than approximately $66 \%$, the deposition velocity is significantly reduced and the pipeline can operate at a low velocity without stationary deposit.

The pipeline velocity is in the range 1.6 to $2.3 \mathrm{~m} / \mathrm{s}$. The graph also shows that the stationary deposition velocity at low concentration is $2.3 \mathrm{~m} / \mathrm{s}$ (equivalent to a flow of $550 \mathrm{~m}^{3} / \mathrm{hr}$ ). With a maximum pump flow of $630 \mathrm{~m}^{3} / \mathrm{hr}(\mathrm{v}=2.63 \mathrm{~m} / \mathrm{s})$, the proposed pumps can flush the pipeline without leaving deposited solids.

The pipeline friction pressure gradients for slurry concentration and flow are shown in Figure 5 for a pipeline internal diameter of $289 \mathrm{~mm}$. At the design concentration of $70 \%$, at a flow rate of $550 \mathrm{~m}^{3} / \mathrm{hr}$, the friction pressure gradient is predicted to be $1.2 \mathrm{kPa} / \mathrm{m}$.

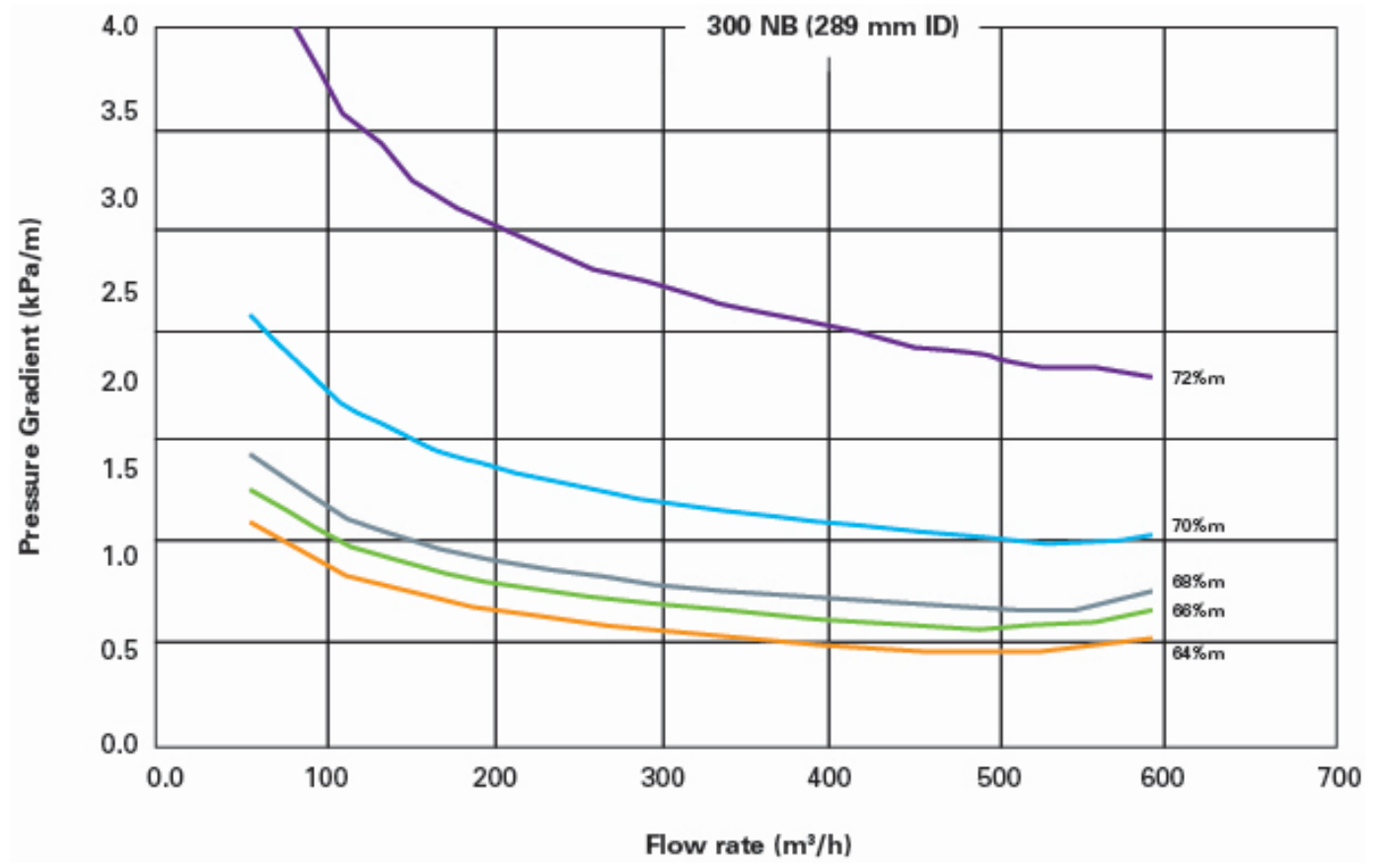

Figure 5 Pipeline pressure gradient for slurry concentration and flow 
The final adopted pipe size was $300 \mathrm{~mm}$ with an outside diameter of $323.9 \mathrm{~mm}$, and a wall thickness of $21.4 \mathrm{~mm}$ (schedule 100), resulting in an inside diameter of $281 \mathrm{~mm}$.

Given that the maximum pumping distance is specified to be $3,000 \mathrm{~m}$ and the vertical lift is $+100 \mathrm{~m}$, the expected pump operating pressure is $5,400 \mathrm{kPa}$ for $70 \%$ and $7,800 \mathrm{kPa}$ for $72 \%$. Including an operational margin, the pump pressure has been finalised at $11,000 \mathrm{kPa}$.

\section{$4 \quad$ Project implementation}

The project was awarded in September 2015. The scope of supply comprised of PD pumps, centrifugal booster pumps, low-pressure knife gate valves, high-pressure ball valves, required pump station instrumentation and software functional design specification (FDS) development and implementation.

The piping and instrumentation diagram (P\&ID) of the pumping system is presented in Figure 6 . Thickened tailings are generated by two thickeners. Underneath each thickener, two centrifugal pumps are located (one in operation and one on standby) to transfer the slurry to the nearby pump station. Isolation valves direct the slurry to strainers that prevent oversized and foreign particles from entering the mainline transportation pumps. The pump station is equipped with three piston diaphragm pumps, normally two in operation and one in standby. Each pump can be connected to one of the main pipelines through high-pressure ball valves located downstream of the PD pumps. The suction strainers are equipped with a pressure transmitter to measure differential pressure and detect strainer blockage. Pressure transmitters are also installed in the main pipelines to measure differential pressure, but with a view towards predicting pump discharge pressures in case of changing slurry conditions. The software FDS enabled development of the DCS software and all sequences were tested during a water run, before the plant was allowed to run on slurry. Online monitoring of all pump station equipment is implemented by the customer to enable future unmanned operation of the pump station. Local operation of equipment is available through tablets. The equipment was delivered to site in May 2016 and the pump system was commissioned in January 2017.

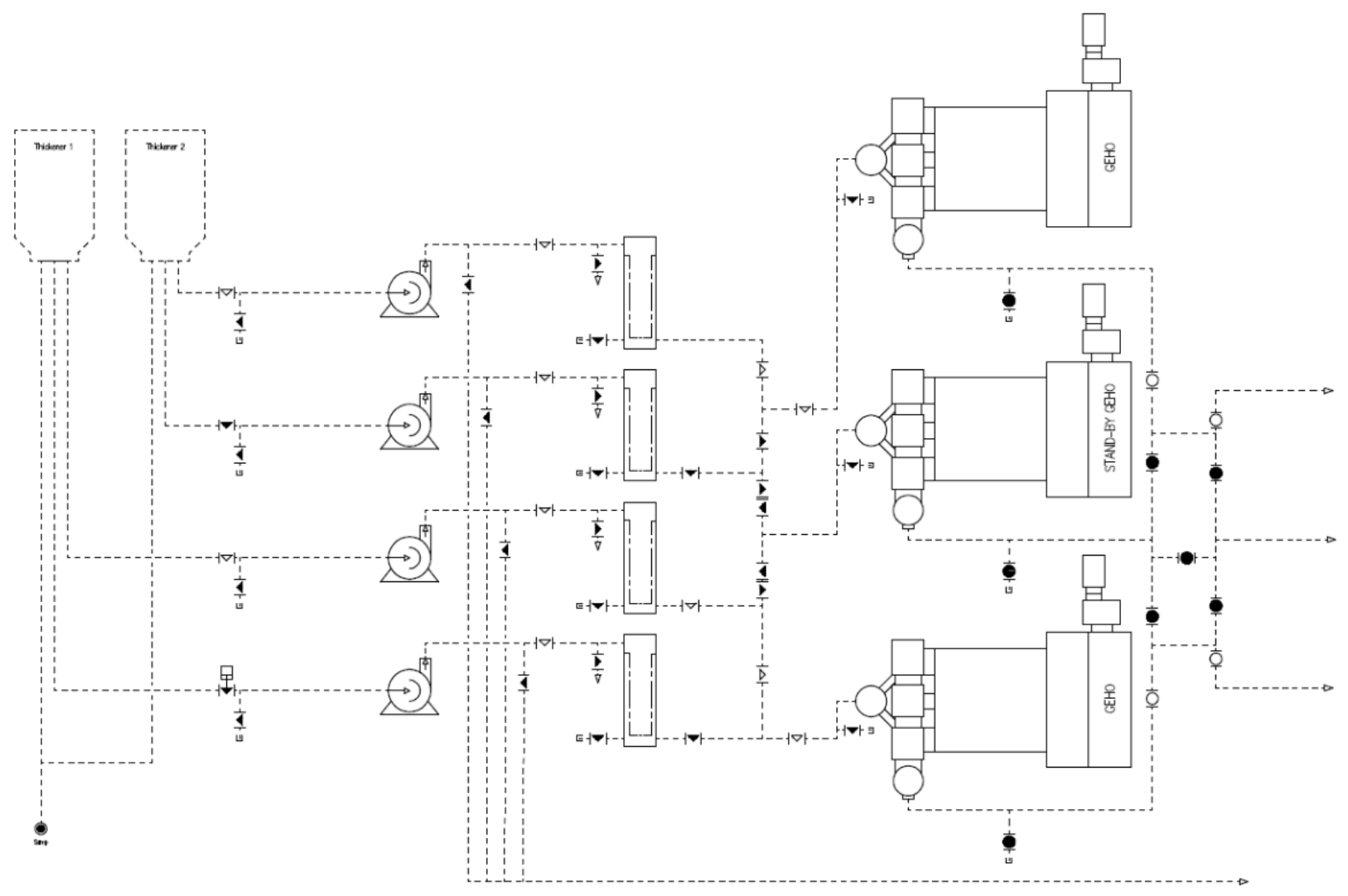

Figure 6 System P\&ID 


\section{$5 \quad$ Operational review after commissioning}

The pumping system (Figure 7) has been in continuous operation since successful commissioning in January 2017.

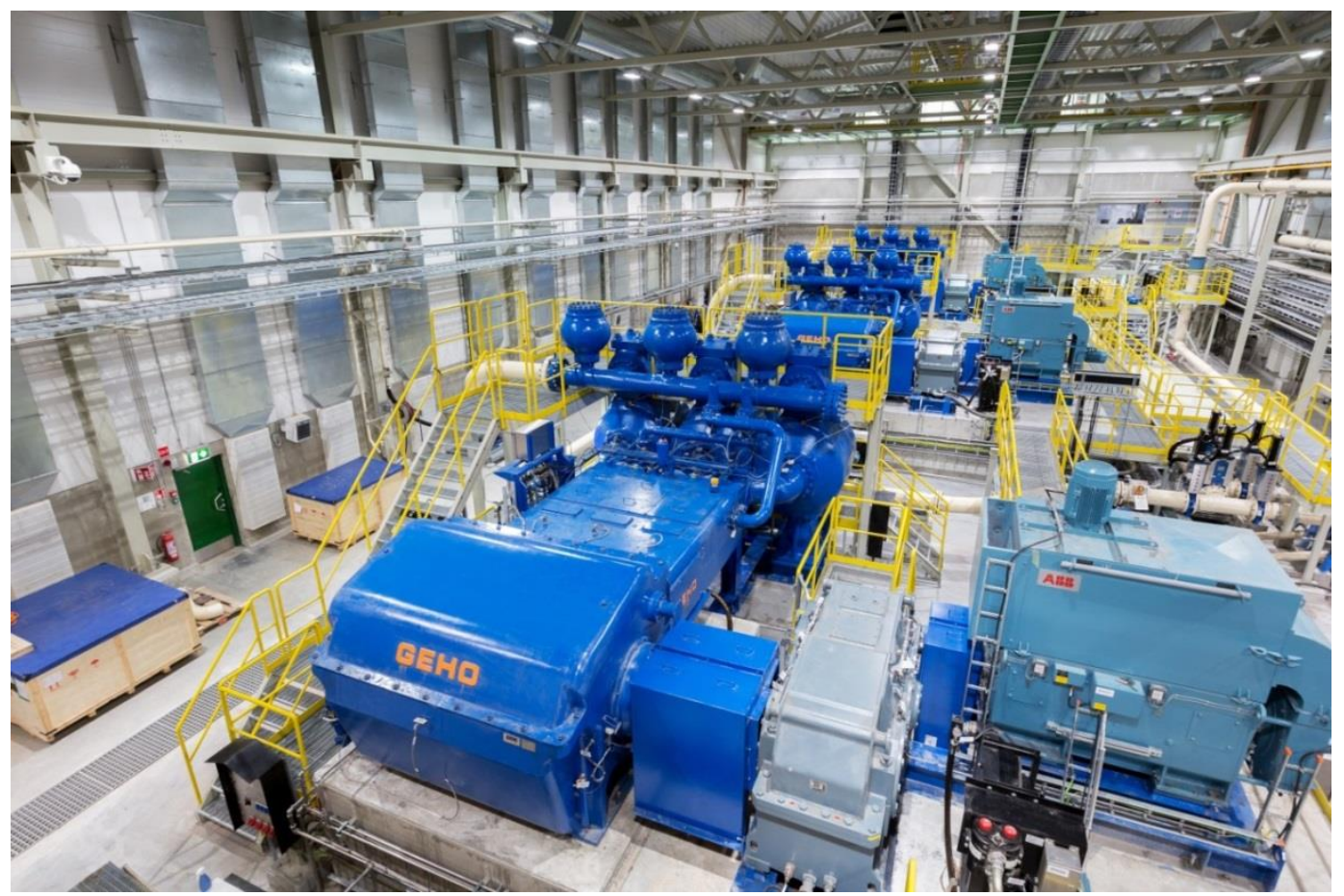

\section{Figure 7 Pump station overview}

The estimated length of the three pumping lines has been reduced to $1,400 \mathrm{~m}$ for line one and two and $1,800 \mathrm{~m}$ for line three. Also, the final height difference has been reduced from +100 to $+40 \mathrm{~m}$. At present, the length of the discharge lines is $440 \mathrm{~m}$ for line one, 1,000 $\mathrm{m}$ for line two and $360 \mathrm{~m}$ for line three (Figure 8).

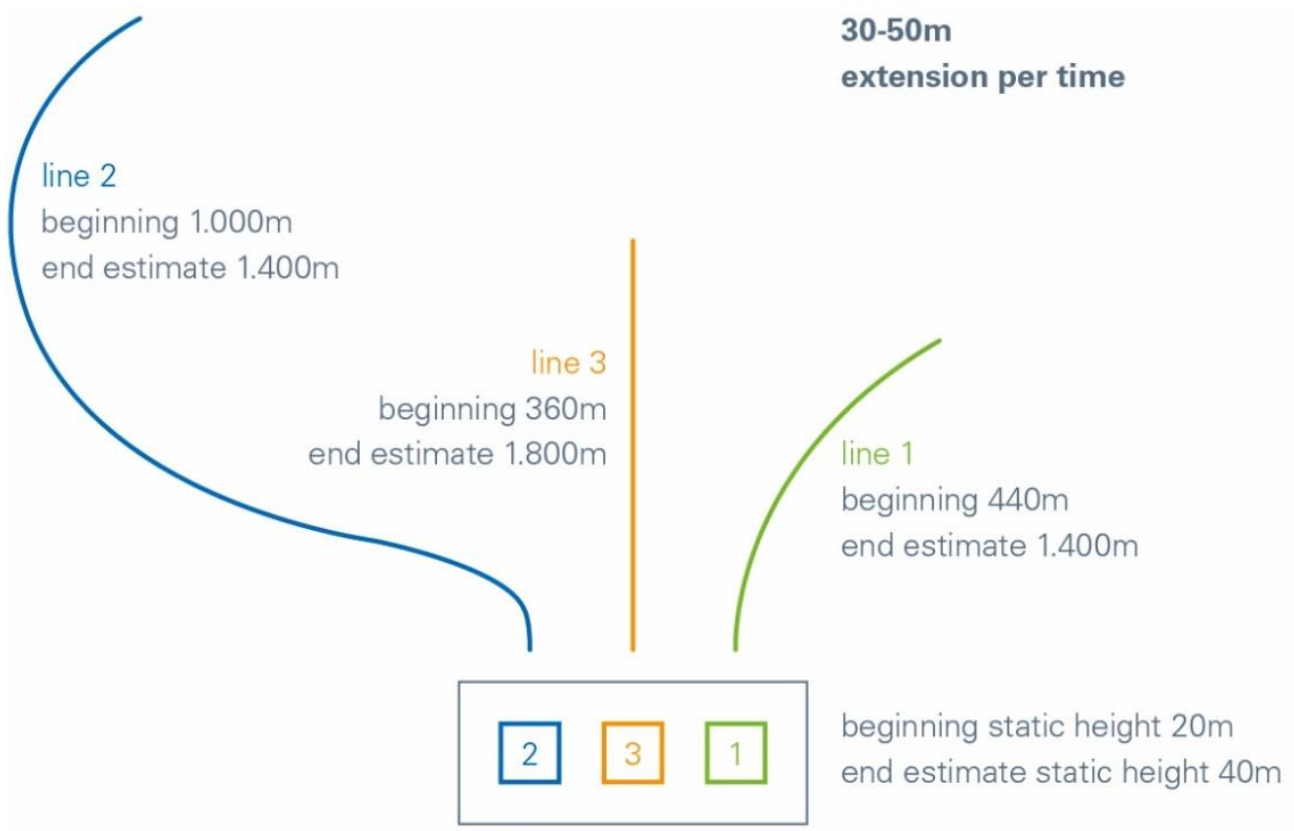

Figure 8 Schematic overview of TSF discharge line 
Two pumps have been pumping the thickened tailings to the disposal area at average pumping pressures between 1 and $6 \mathrm{kPa} / \mathrm{m}$ with spikes of up to $8 \mathrm{kPa} / \mathrm{m}$ during upset conditions (Figure 9).

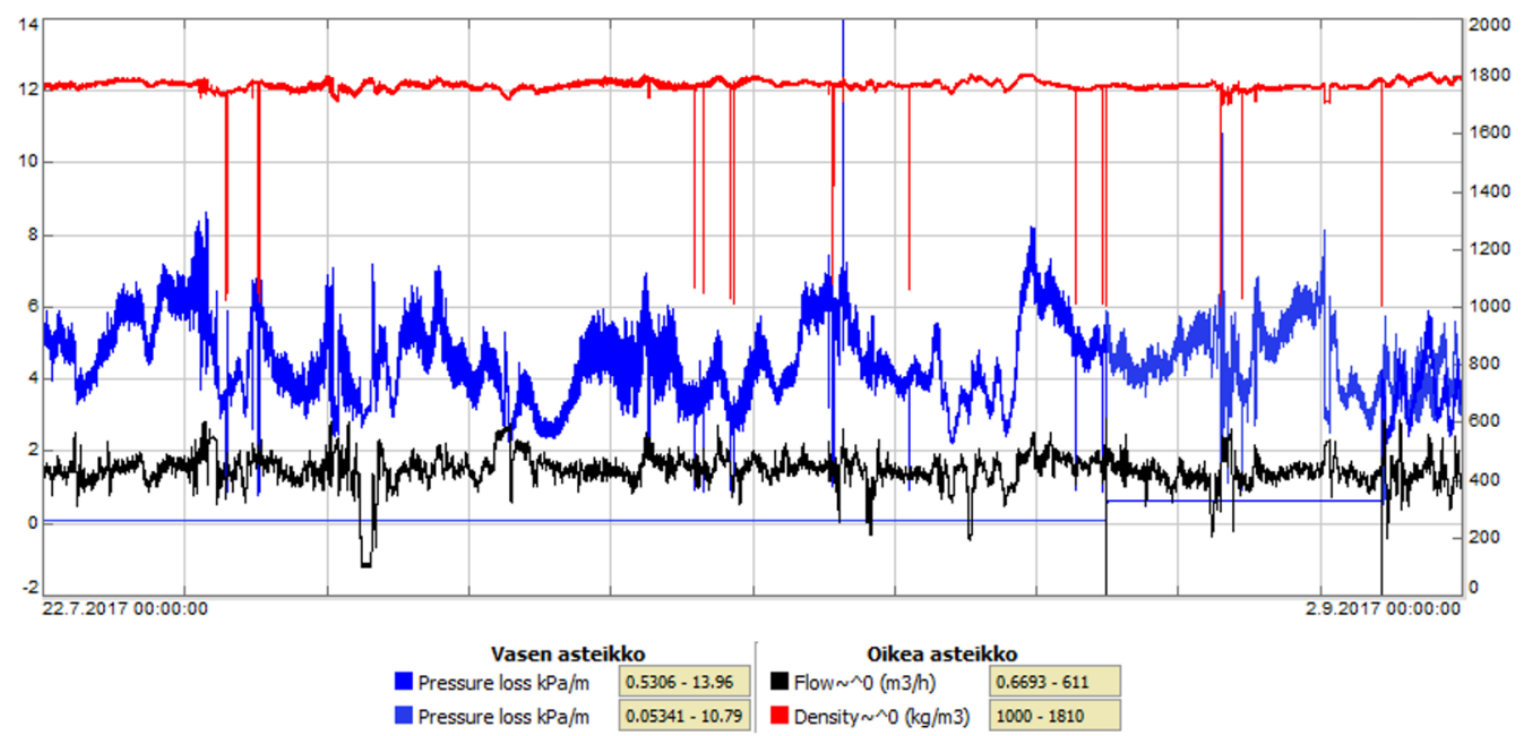

Figure 9 Operational data from Yara plant

There is significant day-to-day variation in tailings composition, depending on ore quality, grindability, planning and possible operational upsets. As these factors may significantly influence the tailings surface chemistry, particle morphology and particle size distribution, the impact on flowing behaviour and operational conditions is evident.

As the $8 \mathrm{kPa} / \mathrm{m}$ pressure requirement would lead to pump discharge pressures exceeding the design values, a future density control system in the suction of the booster pumps will be considered. This solution can prevent the dense slurry from entering the main pipeline. In spite of the slurry being heterogeneous and fast-settling, the pipeline has proven to be reliable. No specific site evaluation with respect to slurry properties and related pressure gradients has been done, but it is apparent that the actual pipeline operating pressures exceed the estimates.

The service life of the PD pump non-return valves has reached 5,000 hrs and there is no visible wear. Some modifications have been made to the strainers, as the pressure drop over the strainers proved to be higher than anticipated. At present, strainer baskets with vertical strips spaced at $25 \mathrm{~mm}$ are used, and the PD pump performance remains consistent. Further trials are planned to remove the strainers completely, as the feed to the thickeners itself is screened for $25 \mathrm{~mm}$ particles. The results at the disposal area are better than expected with deposit angles of around $4^{\circ}$ (Figure 10). In this way, the project goal is achieved and future operation of the Yara plant in Finland secured.

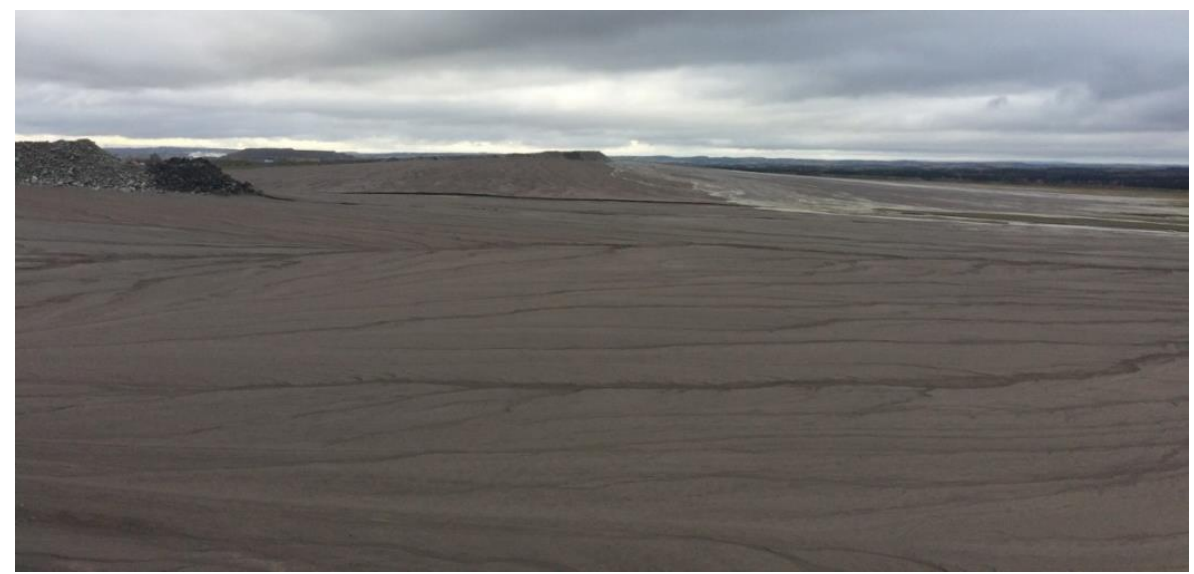

Figure 10 Yara TSF 


\section{Conclusion}

Through close cooperation with carefully selected partners, Yara was able to successfully implement a TTD pumping system, starting with pilot plant testing up to and including successful commissioning. In spite of the challenging slurry conditions, a well-performing pump system was successfully established, enabling pumping of thickened tailings at target solids concentrations, resulting in a slope at the TSF of approximately $4^{\circ}$ and thus increasing storage capacity.

\section{Acknowledgement}

Weir Minerals Netherlands acknowledge Yara for their support on writing this case study.

\section{References}

Shook, C \& Roco, M 1991, Slurry Flow, Principles \& Practice, Butterworth-Heineman, Boston. 
